\title{
"Não me interessam filósofos mortos": uma homenagem a Sergio Luiz de Castilho Fernandes
}

\author{
"I'm not interested in dead philosophers": \\ a homage to \\ Sergio Luiz de Castilho Fernandes
}

\section{Resumo}

O presente texto pretende elaborar uma breve biografia filosófica como homenagem a Sergio Luiz de Castilho Fernandes, tratando de sua obra e ensino de filosofia.

\section{Abstract}

The present text intends to elaborate a brief philosophical biography as homage to Sergio Luiz de Castilho Fernandes, dealing with his work and teaching of philosophy.

O presente texto ${ }^{1}$ é uma homenagem ao professor e filósofo Sergio Luiz de Castilho Fernandes, falecido no dia 20 de setembro de 2018. Pretendo reconstruir aqui alguns elementos da convivência com ele ao longo de cerca de 25 anos, como aluno, orientando e amigo, buscando traçar alguns aspectos, não somente de sua teoria filosófica, como também de sua prática no ensino de filosofia e de sua relação com a academia. Deste modo, o texto que se segue não é propriamente um artigo acadêmico, pelo menos não em

1 Agradeço a Gustavo Leal-Toledo, Camila Jourdan, Rafael Vaz e Iasmim Martins por suas contribuições a elaboração deste texto.

* Departamento de Educação e Sociedade e da Pós-graduação em Filosofia da UFRRJ.

E-mail: leandrochevitarese@yahoo.com.br.

Recebido em: 15/02/2019. Aceito em: 07/07/2019. 
seus moldes tradicionais. Talvez seja uma breve biografia filosófica. Todavia, parece-me que não haveria nada mais justo a ser feito (ainda que seja muito mais difícil para mim fazê-lo), principalmente por se tratar de um professor e filósofo que traz em seu legado a problematização do modo tradicional de fazer filosofia.

Conheci Sergio Fernandes em 1994, quando iniciei minha graduação em filosofia na Universidade do Estado do Rio de Janeiro. Uma das coisas que logo me chamou atenção foi sua pretensão em elaborar uma teoria filosófica própria, contrariando tudo mais que ouvia na academia acerca de tal propósito. Para ele, a filosofia não poderia limitar-se a repetição matraqueada das diversas teorias filosóficas, nem tampouco estar restrita ao estudo da história da filosofia; e não poderia também resumir-se a mera exegese de textos clássicos, acompanhada de uma leitura exaustiva dos mais destacados comentadores. A filosofia exigia o enfrentamento de questões filosóficas, o que não poderia prescindir do desafio de pensar por si próprio.

É claro que pareceria implausível que alguém se aventurasse em tal empreitada sem que antes tivesse passado por todas as experiências anteriores. Sua trajetória de especialista em Filosofia da Ciência, PhD pela London School of Economics and Political Science, onde desenvolveu em sua tese uma crítica à leitura popperiana de Kant, publicada posteriormente em 1985², demostra muito bem isso.

Uma das primeiras vezes que conversamos mais longamente, ainda na inocência de meu primeiro ano de graduação, apresentei-lhe diversas críticas à epistemologia kantiana - tinha lido com afinco toda a Crítica da Razão Pura -, às quais ele ouviu atentamente. Em seguida, disse-me com tranquilidade: "muito bom o que você disse, mas primeiro você deve se concentrar em terminar a sua graduação, depois você faz o mestrado e o doutorado. Quando você for doutor em filosofia, pode dizer o que bem quiser e mandar qualquer um à merda (sic) - aliás, é para isto que servem os títulos acadêmicos. Mas por hora, procure compreender a questão filosófica e a tentativa de resposta elaborada por Kant, já é suficiente". Não foi muito difícil perceber, logo depois, que obviamente ainda não havia entendido quase nada da Crítica da Razão Pura. Compreendi também que ele falava, de certo modo, de sua própria relação com a academia. Acima de tudo, ficou-me claro que filosofia nada tinha a ver com a dialética de "discutir ou refutar as teorias filosóficas", 
nem muito menos "concordar ou discordar" delas, mas, sim, compreender as perguntas e investigar as possíveis respostas. Para tanto, seria necessário, sem dúvida, muito trabalho e dedicação acadêmica, leitura dos clássicos, dos comentadores e da história da filosofia. Mas, por outro lado, não se poderia perder de vista que a própria filosofia consistia, de algum modo, em um tipo de experiência: compreender a pergunta filosófica...

Nesta época ele concluía seu primeiro livro propriamente autoral, Filosofia e Consciência 3 , publicado em 1995. Nesta obra, Sergio Fernandes dedicou-se a uma revisão crítica do modo de compreender a Filosofia na tradição ocidental, trazendo elementos filosóficos da tradição védica e do budismo, como forma de repensar seu próprio estatuto. A partir de uma "reforma radical da Ontologia", como dizia, restabelecendo-a como lugar par excellence da Filosofia, investigou a noção de Consciência, em diálogo com a tradição oriental e a Filosofia da Mente contemporânea, apresentando uma concepção de Consciência "não-fenomenológica". Por vezes, referia-se a sua própria Ontologia como "transfenomenológica". Nesta obra afirma que "o filósofo de ofício, que não seja historiador, trabalha em geral com problemas filosófi$\cos ^{\text {" }}$. Ao mesmo tempo, sustenta a tese, um tanto paradoxal, de que "a única resposta verdadeiramente filosófica é a compreensão das perguntas. Não que esta compreensão leve à, ou cause - melhor, ocasione a resposta: é que essa compreensão é a resposta"5. Para a Filosofia, "a chave só pode estar na compreensão da pergunta, no resistir às tentações opostas, tanto de respondê-la (a "dialética"), quanto de esquecê-la, ou reprimi-la (a "ignorância")6.

Acompanhei assiduamente seus cursos na graduação e elaborei um projeto de Iniciação Científica sob sua orientação. O tema, um dos assuntos abordados em seu livro, era a distinção entre modelos de conhecimento desenvolvidos no Ocidente e no Oriente. Este foi o outro motivo que me aproximou de Sergio, nosso interesse em comum pela Filosofia Oriental. Para minha surpresa, ele possuía e já tinha lido a obra completa de Krishnamurti ${ }^{7}$, minha

3 Fernandes, S. L. de C. Filosofia e Consciência: uma investigação ontológica da distinção entre aparência e realidade. RJ: Areté, 1995.

4 Fernandes, S. Op. Cit., 1995, p.13.

5 Ibidem, p.19.

6 Ibidem, p.4.

7 Krishnamurti, J. The Collected Works of J.Krishnamurti. 17 Vols. Dubuque, Iowa: Kendall / Hunt Publishing Company, 1991. 
principal leitura oriental naquele momento. Ainda hoje a grande maioria dos professores de filosofia, infelizmente, não se interessam pelo pensamento desenvolvido no Oriente. Sem dúvida, a teoria filosófica de Sergio Fernandes deve-se, em grande parte, a este encontro com o Oriente. Minhas leituras na época eram fragmentadas e dispersas, e tive oportunidade de organizá-las e aprofundá-las com a bibliografia que me foi oferecida por ele. Dentre os livros estudados, encontravam-se alguns clássicos, tais como Radakrishnan", Dasgupta $^{9}$ e o Dhammapada de Cohen ${ }^{10}$, contemporâneos como Krishnamurti ${ }^{11}$,

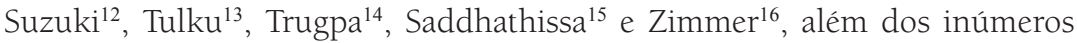
artigos sobre vedanta e budismo, tão elogiados por ele, e presentes na Routledge Encyclopedia of Philosophy ${ }^{17}$. Daí em diante fui seu orientando no bacharelado na UERJ, no mestrado e doutorado na PUC-Rio e construímos também uma amizade que durou até seus últimos dias.

"Não me interessam filósofos mortos". Confesso que demorei algum tempo para compreender o que ele queria dizer com estas palavras. Alguns filósofos deveriam ser esquecidos? Estariam superados? Somente questões filosóficas da atualidade teriam relevância? Deveríamos estudar apenas filósofos em atividade? Seria o caso de rejeitar a história da filosofia? Nada disso. A partir do estudo das diferentes teorias filosóficas desenvolvidas ao longo da história, seria possível ter melhores condições de enfrentar, de fato, problemas filosóficos. Tal feito, não apenas nos proporcionaria melhores condições de tratar de questões que se fazem presentes na atualidade, mas, para ele, acima de tudo, investigar questões que se colocam além de toda a temporalidade. $\mathrm{O}$ que haveria de interessante nos filósofos ao longo da história não poderia se

8 Radakrishnan, S.: Indian Philosophy. 2 Vols. Oxford University Press, 1923.

9 Dasgupta, S.: History of Indian Philosophy. 4 Vols. Delhi: Motilal Barnasidass, 1922.

10 Cohen, N.: A Senda da Virtude - Dhammapada. SP: Editora Palas Athena, 1985.

11 Krisnamurti, J. op. cit, 1991.

12 Suzuki, D.T.: A Doutrina Zen da Não-Mente. SP: Pensamento, 1990.

13 Tulku, T.: Conhecimento de Tempo e Espaço. RJ: Publicações Dharma, 1995.

14 Trungpa, C.: Além do materialismo Espiritual. SP: Cultrix, 1986.

15 Saddhatissa, H. Buddhist Etics. Wisdom Publ, 1987.

16 Zimmer, H.: Filosofias da India. SP: Palas Athena, 1991.

17 Craig, E. (Ed.): Routledge Encyclopedia of Philosophy. London and New York: Routledge, 1998. 
limitar a uma exumação de suas teorias, ou uma exegese fria de suas obras; ao contrário, revelar-se-ia na medida em que tais teorias pudessem nos trazer elementos à experiência do pensamento, de nós, que ainda estamos vivos. $\mathrm{O}$ que pode impedir a "morte" de um filósofo é a possibilidade de que aquilo que foi escrito por ele nos permita melhor pensar filosoficamente, não somente sobre nós mesmos, nossas relações e o tempo em que vivemos, mas, ainda, sobre tudo aquilo que escapa ao tempo - e Sergio Fernandes dedicou sua vida a tal tarefa. Parece-me que, em sua concepção, reduzir qualquer filósofo à mera dissecação de seu cadáver teórico, ao sabor de certo eruditismo acadêmico, seria, aí sim, matá-lo! Talvez por isso dissesse: "Não me interessam filósofos mortos".

Para Sergio Fernandes, a filosofia seria uma forma de, talvez, retirar as pessoas de certo sonambulismo que nos domina a quase todos. Mas isto implicava trazer a filosofia também para uma dimensão prático-existencial, ou mesmo, poder-se-ia dizer, uma dimensão performática. Parece-me que em função de seu apreço pela filosofia oriental, particularmente pelo Budismo Zen, ele procurava, em atitudes simples ou ainda em ações extraordinárias, produzir um certo espanto filosófico acerca de nossa vida ordinária. É claro que ele não estava preocupado com qualquer "resultado" acerca disso. Ele simplesmente fazia. A narrativa de algumas práticas e acontecimentos talvez possa ajudar a ilustrar aqui minha compreensão.

Eventualmente, Sergio respondia a perguntas cotidianas, tais como: "tudo bem?", com um sonoro, "não!", ou ainda, "como vai?", com um vibrante, "mal!", seja acompanhado de uma expressão séria ou de uma gargalhada. Divertia-se depois com a reação das pessoas, pois alguns sequer ouviam o que ele acabara de dizer; outros, constrangidos, seguiam seu caminho como se nada tivessem ouvido; havia também, é claro, quem se irritasse com ele - o que certamente não lhe fazia a menor diferença. Parece-me que seu incômodo repousava, acima de tudo, no automatismo das relações cotidianas, como se todos agissem apenas como zumbis. Por vezes, respondia ainda às mesmas perguntas da seguinte forma: "não sei, não tenho acesso a mim mesmo", ou ainda, "não existe um 'eu' aqui", ou apenas: "como posso saber?". Tal atitude performática, neste caso, fomentava espanto acerca da naturalização em relação à identidade ou à existência de um "eu" que, segundo ele, seria apenas uma construção biopsicossocial, um artefato persistente na mente, articulado pelo pensamento e a pela linguagem. Esta concepção, sem dúvida, encontra-se diretamente relacionada ao zen-budismo. O que se pode ver nesta passagem que ele tanto apreciava: 
Toda nossa percepção sobre o mundo é limitada. Mas por que é que isso acontece? Porque temos a ideia de ego, o egocentrismo. (...) por isto a prática Zen diz: "o treinamento de Zen é aprender sobre si mesmo. Aprender sobre si mesmo significa esquecer de si mesmo. Esquecer de si mesmo significa limpar a ideia de ego. Limpar a ideia de ego é tornar-se a própria Verdade"18.

Gostava de dizer frases que gerassem perplexidade, todas elas, no fundo, trazendo elementos da sua filosofia. Declarava: "Ninguém tem Consciência", "Não se pode perder a Consciência", "Não existem estados alterados de Consciência" - afirmações que são derivações da concepção de Consciência não-fenomenológica, bem como da desconstrução da noção ordinária de "eu", desenvolvida em seu primeiro livro ${ }^{19}$. Ou ainda, defendendo a tese de que o cérebro não pode pensar a si mesmo, mas tão somente o que lhe é externo, afirmava: "não é possível ter Consciência de si" (note-se de passagem: ele sempre odiou Hegel, mas nunca conseguiu esquecê-lo).

Em sua ontologia, o Ser não tem estrutura de duração, o que há são Aparições instantâneas, únicas. Tudo aquilo que é percebido na existência como "objeto" são projeções da Mente, do Pensamento e da Linguagem. A suposta "identidade" de qualquer objeto depende exclusivamente do modo como seu comportamento é percebido na temporalidade. Deste modo, no plano da existência, não há por que haver qualquer diferença, por exemplo, entre "fingir" e "ser". Sendo assim, em sintonia também com certa visão funcionalista, dizia uma frase que incomodava bastante as pessoas: "algo que se comporte exatamente como sua mãe, é a sua mãe".

Sempre estimulava e valorizava os alunos que ousavam pensar por si mesmos. Em certa ocasião, um aluno de graduação, um tanto arrogante, mas muito inteligente, elaborou por si mesmo um argumento filosófico defendendo o dualismo mente-cérebro e lhe entregou discretamente em sala de aula. Sergio puxou uma cadeira para a frente da sala, pediu que ele se sentasse. Leu cuidadosamente cada tópico do argumento, refutando ponto por ponto o que estava escrito. Um pouco de "filosofia ao vivo", como dizia, enfrentando uma questão filosófica.

Certa vez, Sergio havia acabado de ler um livro do qual gostou muito, não me lembro muito bem qual era, mas se tratava de um livro extenso, com bom acabamento editorial e, consequentemente, caro. Passou a aula inteira falando empolgadamente sobre o livro. Ao final, disse que não o queria mais.

18 Tokuda, R.: Psicologia Budista. Rio de Janeiro, 1997.

19 Fernandes, S.L de C. Op. Cit., 1995. 
Perguntou então quem gostaria de levar o livro. Houve um silêncio na sala. Talvez por constrangimento ou pela surpresa da proposta, ninguém se manifestou. Sergio então, literalmente, jogou o livro pela janela do nono andar da UERJ, e continuou a aula mudando de assunto, para a perplexidade dos presentes. Aquilo que por um lado não poderia deixar de ser visto como um gesto de excentricidade, por outro lado, materializava, como na atitude Zen tão admirada por Sergio, o princípio budista de que o conhecimento se assemelha a uma "jangada": pode-se atravessar um rio com ela, mas depois não se deve carregá-la às costas. Do mesmo modo, como ele próprio havia escrito:

Aquilo de que no Ocidente apenas nos aproximamos, sob a forma atitudinal (erigida em método) de "suspensão do juízo" é, no Buda, o desapego ao conhecimento, que é sempre dual. E estar desapegado de um conhecimento que se tem, é muitíssimo diferente de negá-lo. Pelo contrário, é condição sine qua non para usá-lo com espontaneidade, sem ser por ele "usado"2o.

Não somente o conhecimento deve ser "usado com espontaneidade", sem que sejamos "dominados" por ele, mas também repousava aqui a concepção de Sergio sobre a própria linguagem. Gostava de citar Wittgenstein exclusivamente para invertê-lo: "sobre aquilo que não se pode falar, aí sim, vale a pena falar". A linguagem, como parte integrante da estrutura "Mente, Pensamento e Linguagem" - que ele denominava MPL - não apenas produz a ilusão do "eu", como também projeta toda a existência. Todavia, isto não significa de modo algum que ela deva ser abolida, mas, sim, usada como instrumento (como na história de Humpty-Dumpty ${ }^{21}$, que ele não se cansava de contar...). Referindo-se à linguagem, gostava de afirmar: "o dedo aponta para a lua: o sábio olha para a lua; o tolo, para o dedo"22. A passagem original do Lankavatara Sutra, que está na origem de tal formulação, e parece-me pelo menos sugerir adequadamente sua compreensão sobre a linguagem, é a seguinte:

Que os jovens tenham cautela ao se apegar às palavras, julgando que estas correspondam totalmente ao seu sentido, pois a verdade não está encerrada em letras. Quando uma pessoa aponta para algo com o dedo, a ponta

20 Ibidem, p. 37.

21 Humpty-Dumpty é uma personagem do romance de Lewis Carroll, Alice no País das Maravithas, que fazia as palavras significassem exatamente o que ele desejasse, por que ele era o "mestre".

22 Fermandes, S. Op. Cit., 1995, Prefácio XVII. 
deste pode, por simploriedade, ser tomado como o objeto indicado. Assim como crianças, os ignorantes são capazes de abandonar a ideia de que "na ponta do dedo" da palavra está contido todo o seu significado. Não podem imaginar a realidade superior, muito menos realizá-la em si mesmos, pois estão apegados às palavras, que não deveriam ser mais do que um dedo que indica - pois a verdade está do outro lado da palavra ${ }^{23}$.

Eventualmente lecionava na graduação sentado em posição de lótus, em cima da mesa da sala. Também gostava muito de contar histórias Zen durante a aula, ainda que estivesse falando sobre Filosofia da Ciência ou qualquer outro assunto. Certa vez, entrou em sala e ficou em silêncio. Disse apenas: "a figura do professor é como o lugar do mestre, e vocês devem desconstruir o lugar do mestre, então não vou falar nada". E permaneceu em silêncio. Isto produziu grande constrangimento entre os presentes. Alguns foram embora, outros permaneceram em silêncio. Depois de algum tempo, alguns começaram a formular questões para ele, que respondia apenas: "não sei...". E isto durou um tempo que pareceu infinito.

Neste período, em que pesquisava para a elaboração de sua Antropologia Filosófica e sua Filosofia da Religião, Sergio morava em um sítio alugado em Itaipu, Niterói, com cerca de cinquenta gatos e uns oito cachorros. Tinha um caseiro para cuidar de tudo. Não somente a casa era alugada, mas também todos os aparelhos de ar-condicionado, a geladeira, além de outras coisas; dizia ele: "quando dá problema, eu ligo que eles trocam no mesmo dia, não preciso pensar sobre isso". Esta era a mesma relação que tinha com seu vestuário. Uma vez lhe perguntaram por que se vestia sempre com roupas sociais para ir a Universidade se, como ele dizia, não existia um "eu". Ele respondeu apenas: "para não ter que pensar sobre isso". Também havia se desfeito de quase toda sua biblioteca. Os poucos livros que restavam em sua casa, principalmente sobre Filosofia Oriental, foram todos encapados ou pintados de branco. Não se podia enxergar na estante nenhum título, nenhum nome. Aliás, tudo mais na casa era absolutamente branco. Ele havia pintado tudo de branco. Segundo ele, isto lhe ajudava a buscar inspiração.

De fato, ao refletir sobre o conjunto de sua obra em seu último escrito, Deus: A Experiência de Ser Humano ${ }^{24}$, Sergio Fernandes afirma que sua conclu-

23 Lankavatara Sutra; apud Govinda, L. A. Reflexões Budistas. SP: Siciliano, 1993, pp. 44 / 45.

$24 \mathrm{O}$ mencionado texto, elaborado originalmente em formato de livro, encontra-se publicado postumamente na presente edição da Revista $O$ que nos faz pensar, PUC-Rio. 
são, e por que não dizer, toda a sua teoria filosófica, "se origina do que vou chamar de uma 'intuição racional', (...) puro exercício da razão no plano especulativo da Ontologia, ou teoria geral do Ser enquanto Ser. O mais próximo equivalente é o inglês 'insight".

Em 1998, ingressei no mestrado em filosofia na PUC-Rio sob sua orientação. Os cursos de pós-graduação de Sergio Fernandes seguiam sempre a mesma metodologia e, segundo ele, tal encaminhamento já vinha de longa data. Em cada semestre, as primeiras semanas de curso eram reservadas para que o professor apresentasse e discutisse com os alunos a pesquisa que estava realizando naquele momento. Desta forma, os alunos tiveram oportunidade de conhecer e debater muitas das ideias e concepções filosóficas que foram sendo desenvolvidas ao longo dos anos, muitas delas já presentes em Filosofia e Consciência, além das formulações teóricas que acabariam por resultar nos dois livros produzidos subsequentemente, que tratam de Antropologia Filosófica e de Filosofia da Religião. O resto do curso consistia na apresentação de seminários em que cada pós-graduando, do mestrado ou do doutorado, apresentava e discutia com o grupo seu "problema de pesquisa", ou o estado atual de desenvolvimento de sua dissertação ou tese. Tal dinâmica se fazia presente não importando qual fosse o tema ou o autor sobre o qual trabalhava o pós-graduando. Sergio Fernandes promovia intervenções críticas em relação ao que estava sendo apresentado, favorecendo uma melhor delimitação dos problemas de pesquisa e de seu desenvolvimento, estimulando o grupo ao mesmo tipo de participação.

Interessante observar que a dinâmica ali empregada divergia em grande aspecto do trabalho desenvolvido ordinariamente nos grupos de pesquisa. Embora muitos dos presentes fossem seus orientandos, não se discutia propriamente nenhum autor, tema ou linha de pesquisa. Mesmo entre seus orientandos havia grande diversidade: ao longo dos anos sugiram pesquisas em Filosofia da Ciência, Filosofia da Mente, Filosofia da Biologia, Antropologia Filosófica, Filosofia da Religião, Mística e Filosofia, etc. Além disso, eventualmente aceitava orientar pesquisas sobre filósofos que afirmava "não conhecer muito bem" (sobre aqueles que realmente não suportava dizia ironicamente: "não li e não gostei"). Também assumia a orientação de trabalhos cujo conteúdo discordava inteiramente. Certa vez, em uma banca de um aluno seu, disse: "o que você escreveu é um completo disparate, não concordo com nada disso, é francamente um absurdo (em tom ríspido); mas o trabalho é muito competente, está excelente (suavizando a voz)". Sobre orientação de pesquisa, Sergio costumava dizer: "eu oriento pessoas, não autores 
específicos, o que me importam são as questões filosóficas". Aliás, quando lhe apresentei minha proposta de um doutorado em Schopenhauer, ele disse: "nunca li Schopenhauer" (diga-se de passagem: isto obviamente não era verdade!), e completou: "mas você deve saber o que está fazendo, tudo bem, vou ser um leitor crítico".

Nos seminários de pesquisa de pós-graduação de Sergio Fernandes havia uma metodologia de trabalho que de certa forma buscava materializar sua própria concepção de "filosofia", tal como desenvolvida em Filosofia e Consciência. O professor referia-se aos seminários como "laboratórios de pensamento", onde as pesquisas em desenvolvimento eram apresentadas e discutidas sempre com ênfase nos "problemas filosóficos". Costumava dizer: "você precisa enfrentar um problema filosófico como quem segura o touro pelos chifres".

É claro que, como em qualquer laboratório, nem sempre "dava certo" a experiência, ao mesmo tempo em que, por vezes, surgia algo que maravilhava a todos. Em geral, deveria haver sempre algum tipo de "risco" envolvido. Para ele, uma aula de filosofia totalmente planejada, já estava fadada ao fracasso antes de ser iniciada. Eventualmente, falava exatamente o contrário do que pensava sobre o assunto que estava sendo discutido, apenas para ver a reação do expositor. Por vezes, argumentava ferozmente contra o que estava sendo apresentado, ou formulava questões sobre o problema e auxiliava o expositor com sugestões críticas; ou apenas ficava em silêncio, dizendo algo surpreendente ao final do seminário, enfim, ninguém sabia o que iria acontecer em suas aulas antes do próprio fato se consumar. De qualquer modo, não podemos perder de vista que Sergio, por vezes, dizia: "hoje em dia fujo da coerência como o diabo foge da cruz. Um filósofo coerente, é um filósofo morto".

Certa vez, ao perceber uma razoável inconsistência argumentativa em um projeto de doutorado que estava sendo apresentado em seu seminário, ele produziu uma sequência de perguntas que conduziu o argumento a uma reductio ad absurdum, evidenciando que o discente estava a pressupor o que haveria de ser demonstrado. Como seu interlocutor continuava sem compreender o que havia ali acontecido, Sergio deu um sonoro tapa na mesa, levantou-se e saiu em silêncio. Nos instantes seguintes, houve grande desconforto em todos nós.

Sergio também era conhecido por suas reações inesperadas. Poderia repentinamente agir de modo grosseiro ao se irritar com algo, enquanto por vezes falava docemente sobre compaixão, por um tempo incalculável. Certa vez, ao aceitar uma orientação de graduação, perguntou ao aluno se poderia adquirir os livros indicados - ele sabia que o aluno trabalhava e estudava. $\mathrm{O}$ 
discente respondeu que sim, não precisava se preocupar que ele daria um jeito. Então ele sacou um cheque, assinou e entregou para ele dizendo: "os livros são importados e caros, leve o cheque, a única condição é que você disponibilize para outros alunos e orientandos quando terminar de lê-los". E se retirou.

Em 2001, publicou pela primeira vez, em formato de artigo, os resultados preliminares de sua teoria em Filosofia da Religião: O Ser Humano como Experiência Divina: Esboço de uma Teoria em Filosofia da Religião $0^{25}$. Gostava muito deste texto e costuma usá-lo em sala de aula com os alunos.

Neste contexto, em certa ocasião, quando perguntado sobre a relevância de estudar a experiência religiosa na atualidade, Sergio disse: "bom, se você está em dúvida, faça o seguinte experimento: pegue um tijolo, sim um tijolo, e ponha em um altar; reze para ele todos os dias; confesse a ele suas angústias e lhe peça o que anseia; faça isto, digamos, por alguns meses, não é necessário muito tempo. Mas faça com afinco, com toda sua energia, como se sua vida dependesse disto. Depois, apenas tente retirar o tijolo do altar e veja o que acontece...". É claro que se tratava aqui de uma provocação filosófica em tom irônico, "altares, rezas, confissões e pedidos" estavam bem longe daquilo que Sergio compreendia como Experiência Religiosa.

Em 2002, Sergio Fernandes já havia concluído seu livro sobre Antropologia Filosófica e me enviou a primeira versão para leitura e comentário. Apenas em 2005, quando já havia acabado de concluir o doutorado, foi publicado então seu segundo livro propriamente autoral: Ser Humano: um ensaio em antropologia filosófica ${ }^{26}$. Nesta obra, retomando os fundamentos da "reforma ontológica" desenvolvida em Filosofia e Consciência, Sergio Fernandes elabora sua teoria em Antropologia Filosófica, tratando tal disciplina como um capítulo da sua Ontologia da Experiência. Ao leitor, ele já avisa na introdução que sua obra está "impregnada" dos elementos de sua Filosofia da Religião, ainda a ser concluída em um próximo livro.

A teoria ali desenvolvida afirma que Ser e Existir são dois lados de uma mesma moeda. A "verdadeira natureza" de tudo que existe não pode repousar em sua própria existência, deve-se buscar o seu Ser. A pergunta acerca do "Ser em si" teria, portanto, precedência sobre a investigação do nosso próprio ser. Partindo então da aplicação de sua teoria ontológica ao problema em

25 Fernandes, S. L. de C. O Ser Humano como Experiência Divina: Esboço de uma Teoria em Filosofia da Religião. Crítica (UEL), Londrina, PR, v. 6, n.22/Jan.-Ma, pp. 181-212, 2001.

26 Fernandes, S. L. de C. Ser Humano: um ensaio em antropologia filosófica. RJ: Ed. Mukharajji, 2005 . 
questão, o Ser Humano é apresentado como "Experiência em si" ou "Ser como Experiência" (distinguindo-se do Ser enquanto Ser). Deste modo, somos Experiências, não as temos. Todavia, a Mente, o Pensamento e a Linguagem produzem a impressão de que há um "eu experienciador". A "Presença de Espírito" corresponderia à Compreensão de nossa verdadeira natureza e, portanto, ao estabelecimento de outra relação com o "instrumento" da Mente, do Pensamento e da Linguagem. Neste livro, também retoma o diálogo com a Ciência, acima de tudo para "recolocá-la em seu lugar", pois nenhuma teoria científica poderia ser relevante para tratar de questões ontológicas. Por fim, elabora uma desconstrução da problemática Ética, pelo menos do modo com a tradição ocidental a apresenta, seja como Ética Descritiva, Ética Normativa ou Metaética.

Em 2007, aposentou-se da PUC-Rio - já era aposentado na UERJ - e viveu a década seguinte de modo bastante simples, recluso e mantendo contato com pouquíssimas pessoas. Enfrentou dificuldades financeiras e períodos de depressão. Durante anos não conseguiu escrever nada. Meses se passavam em que não lia absolutamente nada, "nem jornal", ele dizia. Por vezes encontrava algum livro interessante e devorava-o rapidamente. Saía de casa apenas quando era estritamente necessário. Não via televisão nem ouvia rádio, escutava música clássica e assistia a alguns filmes, em geral "tolices", como dizia. Na sua modesta casa, viam-se budas, um único quadro de paisagem, pouquíssimos livros na estante, o ar-condicionado estava sempre ligado e o cheiro de incenso adornava o ambiente. Procurava visitá-lo com alguma regularidade. Bebíamos sempre café forte, depois do qual ele fumava um hollywood azul, e então falávamos amenidades, conversávamos sobre filosofia e sobre a vida. Certa vez me perguntou: "você não tem uma questão filosófica?", respondi: "certamente, não como você", "não acho que tenha possibilidade de resolver nenhuma questão, sou apenas um professor de filosofia". Ele me olhou com alguma tristeza ${ }^{27}$. De qualquer modo, sabia exatamente o que ele queria dizer com a pergunta. Angustiava-se por não ter conseguido ainda escrever o livro que considerava ser seu último desafio: um livro sobre a experiência religiosa, sua filosofia da religião. Tenho a singela impressão de que foi isto que o manteve na existência durante esta década.

27 Sobre o tema da tristeza, vale considerar, que lhe era bem-vinda e louvável, pelo menos em certo aspecto. Uma vez, quando já estava aposentado, apresentei-lhe uma doutoranda em filosofia que queria muito conhecê-lo. Depois de uma longa conversa, ele disse para ela: "você tem a tristeza necessária para fazer filosofia". 
No segundo semestre de 2017 concluiu seu terceiro livro autoral, que ele compreendia como um acabamento do conjunto de sua obra: Experiência Religiosa: notas para uma filosofia da religiã $0^{28}$. Ao me entregar os originais para leitura e comentário, disse: "meus livros têm sido publicados a cada dez anos, este está um pouco atrasado". Nesta obra, Sergio Fernandes elabora o que chamaria de Metafísica da Experiência Religiosa, analisando a estrutura de tal experiência em três dimensões: a Mística, a Profética e a Sagrada. Cada uma delas corresponderia, respectivamente, a altura, profundidade e largura de um tetraedro que expressa a estrutura da experiência religiosa que é própria a todos nós, independentemente de qualquer concepção autodeclarada acerca de religiosidade ou ateísmo.

Em sentido estrito, na teoria de Sergio Fernandes, Deus não existe, Ele apenas é. Existir (ex-sistere) é estar fora do Ser. Deus coincide com o Ser. Deus não tem Face, Ele usa máscaras e nós somos suas Experiências. Tal como o Ser se "projeta" na Existência, o Ser Humano é uma Experiência de Deus. Deste modo, ninguém tem Experiência de Deus, pois somos Experiências de Deus. Deus é Impessoal e Amoral. O "Mal" surge da ignorância, do Esquecimento do Ser e da subordinação à Mente, ao Pensamento e à linguagem, o que gera a identificação com o "eu", pelo qual passamos a acreditar que somos o que pensamos ser. O "Bem" advém da Presença de Espírito, da Lembrança do Ser e da Compreensão (equânime, sem qualquer julgamento) de tudo aquilo que é projetado pela Mente, Pensamento e Linguagem, cujo nobre fruto se revela na Compaixão por todos os seres.

Em sua trajetória acadêmica, parece-me que Sergio Fernandes sempre procurou fazer o que recomendava aos seus alunos: "enfrentar o touro segurando-o pelos chifres". Durante toda sua vida perseguiu, desafiou e enfrentou algumas das questões filosóficas fundamentais. Tal tarefa, em sua concepção, não poderia prescindir do desafio de elaborar sua própria teoria filosófica, como ele mesmo afirma na introdução de seu último escrito, Deus: A Experiência de Ser Humano ${ }^{29}$. Sergio Fernandes faleceu apenas alguns meses depois de concluir aquele que já considerava ser seu último livro, no qual enfrentou a tarefa de explicar para o público em geral sua filosofia. Desde que o conheço - e já havia sugerido diversas vezes que ele escrevesse tal texto

28 Fernandes, S. L. de C. Experiência Religiosa: notas para uma filosofia da religião. RJ: Ed. Mukharajji, (no prelo).

29 O mencionado texto, elaborado originalmente em formato de livro, encontra-se publicado postumamente na presente edição da Revista O que nos faz pensar, PUC-Rio. 
mais "didático" - sempre me disse que isto seria muito mais difícil para ele do que concluir sua própria teoria filosófica. Há anos pensava que em algum momento acabaria arriscando-me a escrever uma versão mais didática de sua obra, mas não foi preciso, ele mesmo a fez, permitindo-me agora escrever, pelo menos como tentativa, uma breve biografia filosófica. Sinto que ele se divertiria se pudesse lê-la. Para aqueles que pretendem conhecer sua obra, o trabalho de toda uma vida dedicada à filosofia, minha sugestão é que iniciem a leitura por este último escrito e em seguida leiam na ordem de publicação os seus artigos e livros.

Sempre falou com naturalidade sobre a morte: "tenho medo apenas do sofrimento, jamais da morte", dizia. Quando adoeceu, isto me permitia brincar com ele dizendo: "por gentileza, não morra esta semana, porque pretendo visitá-lo na quinta depois da aula". Ele ria e dizia: "tudo bem, vou esperá-lo então". Poucos dias antes de falecer, quando conversamos longamente ao telefone, ele me disse: "já paguei meu galo a Asclépio", e deu uma gargalhada...

Que Sergio Luiz de Castilho Fernandes nunca seja um filósofo morto.

\section{Referências}

COHEN, Nissim: A Senda da Virtude - Dhammapada. SP: Editora Palas Athena, 1985. CRAIG, E. (Ed.): Routledge Encyclopedia of Philosophy. London and New York: Routledge, 1998.

DASGUPTA, S.: History of Indian Philosophy. 4 Vols. Delhi: Motilal Barnasidass, 1922. FERNANDES, S. L. de C. Foundations of Objective Knowledge. The Relations of Popper's Theory of Knowledge to that of Kant. Dordrecht: D. Reidel, 1985

Filosofia e Consciência: uma investigação ontológica da distinção entre aparência e realidade. RJ: Areté, 1995.

. O Ser Humano como Experiência Divina: Esboço de uma Teoria em Filosofia da Religião. Crítica (UEL), Londrina, PR, v. 6, n.22/Jan.-Ma, pp. 181-212, 2001.

Ser Humano: um ensaio em antropologia filosófica. RJ: Ed. Mukharajji, 2005. Experiência Religiosa: notas para uma filosofia da religião. RJ: Ed. Mukharajji, no prelo.

Deus: A experiência de Ser Humano. O que nos faz pensar? PUC-Rio, no prelo. GOVINDA, L. A.: Reflexões Budistas. SP: Siciliano, 1993.

KRISHNAMURTI, J. The Collected Works of J.Krishnamurti. Dubuque, 17 Vols. Iowa: Kendall / Hunt Publishing Company, 1991. 
516 Leandro Chevitarese

RADAKRISHNAN, S.: Indian Philosophy .2 Vols. Oxford University Press, 1923.

SADDHATISSA, H. Buddhist Etics. Wisdom Publ, 1987.

SUZUKI, D.T.: A Doutrina Zen da Não-Mente. SP: Pensamento, 1990.

TOKUDA, R.: Psicologia Budista. Rio de Janeiro, 1997.

TULKU, T.: Conhecimento de Tempo e Espaço. RJ: Publicações Dharma, 1995.

TRUNGPA, C.: Além do materialismo espiritual. SP: Cultrix, 1986.

ZIMMER, H.: Filosofias da India. SP: Palas Athena, 1991. 